Eastern Illinois University

The Keep

Masters Theses

Student Theses \& Publications

1972

\title{
The Effects of the Four Psychological Primary Colors on GSR, Heart Rate, and Respiration Rate
}

Keith W. Jacobs

Eastern Illinois University

This research is a product of the graduate program in Psychology at Eastern Illinois University. Find out more about the program.

\section{Recommended Citation}

Jacobs, Keith W., "The Effects of the Four Psychological Primary Colors on GSR, Heart Rate, and Respiration Rate" (1972). Masters Theses. 3911.

https://thekeep.eiu.edu/theses/3911

This is brought to you for free and open access by the Student Theses \& Publications at The Keep. It has been accepted for inclusion in Masters Theses by an authorized administrator of The Keep. For more information, please contact tabruns@eiu.edu. 
TO: Graduate Degree Candidates who have written formal theses.

SUBJECT: Permission to reproduce theses.

The University Library is receiving a number of requests from other institutions asking permission to reproduce dissertations for inclusion in their library holdings. Although no copyright laws are involved, we feel that professional courtesy demands that permission be obtained from the author before we allow theses to be copied.

Please sign one of the following statements.

Booth Library of Eastern Illinois University has my permission to lend my thesis to a reputable college or university for the purpose of copying it for inclusion in that institution's library or research holdings.

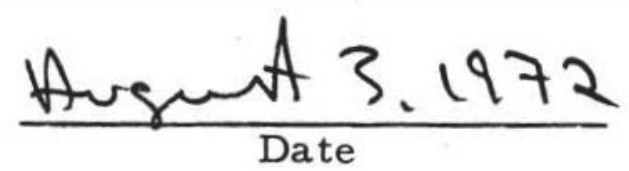

I respectfully request Booth Library of Eastern Illinois University not allow my thesis be reproduced because 


\section{THE FFFECTS OF THE FOUR PSYEHOIOGICAL PRIMARY \\ $\frac{\text { COLORS ON GSR, HEART RATE, AND RESPIRATION RATE }}{\text { (ITLE) }}$}

BY

KEITH W. JACOBS

$=$

B.A., University of Northern Iowa, 1968

THESIS

SUBMITTED IN PARTIAL FULFILLMENT OF THE REQUIREMENTS

FOR THE DEGREE OF

MASTER OF ARTS

IN THE GRADUATE SCHOOL, EASTERN ILLINOIS UNIVERSITY CHARLESTON, ILLINOIS

1972

YEAR

I HEREBY RECOMMEND THIS THESIS BE ACCEPTED AS FULFILLING

THIS PART OF THE GRADUATE ABOVE
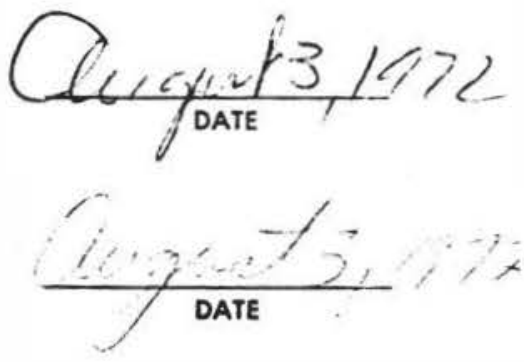
APPROVED BY THE THESIS COMMITTEE:

(signed) 
Measuirement of GSR, heart rate, and respiration rate were taken on twerty-four male s's during presentation of four colors (red, yellow, green, blue). Four sequences of color presentations were used based on a 4 by 4 latin square with six subjects receiving each presentation. Significant color effects ( $p(.05)$ were found when GSR was used as the measure of activation. The most arousing color was red, followed by green, yellow, and blue, with significant differences in arousal value found between colors. Significant trial effects, disregarding colors, were found in respiration rate. Nc significant effects on heart rate were found as a function of trials or color. The arousal values of the colors do not support either a linear or U-shaped function of wave length. 


\section{ACKNOWLEDGENENTS}

This research was possible through the efforts of Dr. Frank Hustmyer who for the past year encouraged me to pursue this area of research and served as chairman for this thesis. Grateful appreciation is also given to Dr. Randall H. Best, Dr. Harold Coe, and Mr. Boyd Spencer who served as committee members and offered their advise and assistance. Finally, I must express my gratitude to my parents whose love and support made this part of my career possible. 
Page

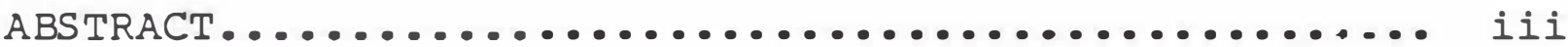

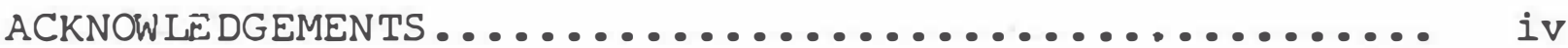

LIST OF TABLES ............................ vi

LIST OF FIGURES ........................... vii CHAPTER

I. INTRODIJTION ............................ 1

A. Historical Background of Problem........... 1

3. Statement of Hypothesis................. 14

II. EXPERIMENTAL METHODOLOGY................. 15

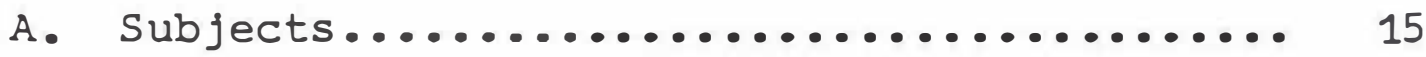

B. Stimuli Colors........................ 15

C. Apparatus............................. 17

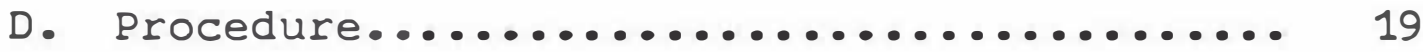

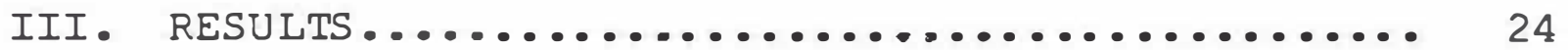

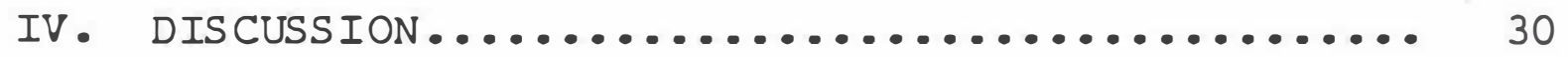

A. Color Effects......................... 30

B. Response Habituation................. 33

C. Response System Specificity............. 34

D. Suggestions for Further Research......... 37

REFERENCES................................ 40

APPENDICES .................................... 44

I. INSTRUCTIONS ........................... 45

II. STATISTICAL ANALYSIS OF RESULTS............ 47

III. ORIGINAL DATA....................... 51 


\section{LIST OF TABLES}

Table

Page

1 Summary of Physiological changes.............. 26

2 Arousal Values of the Four Colors.............. 28

3 Response Habituation...................... 34

4 Response system specificity................. 36 


\section{LIST OF FIGURES}

Figure

Page

1 Arousal Values of Visible Hues (Wilson, 1966)...

7

2 Sumnary ef Previous Resiarch................. 13

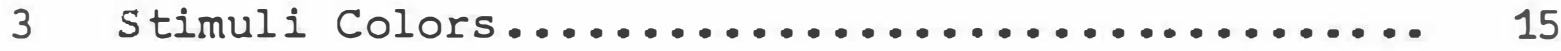

4 Order of Stimuli Presentations............... 22

5 Latin Square.......................... 23

6 Arousal Values of Four Colors................ 27

7 Changes in Respiration Rate by rrial......... 29 
CHAPTER I

INTRODUCTION

Historical Background of Problem.

The assumption is frequently made that people are affected psychologically by colors. This assumption is being applied in the areas of advertising, art education, commercial art, theater, architecture, and television; and is being applied as though the relationships have been proven. The assumption is further made that these psychological effects can be measured on a physiological level.

This basic assumption is presented without guestinn in one of the leading advertising references today, which states that:

Color arouses emotions. Contrary to popular belief, color is not related to vision alone.... As a rule, red also serves as a stimulant; it shakes up the brain, quickens the pulse (Baker, 1961, p. 96).

A similar statement has been advanced by one of the noted authorities in the area of color and art education, in which he reports that:

The polygraph, or lie detector, measures pulse, blood pressure, perspiration, skin temperature, all of which may change under exposure to different colors and degrees of brightness (Birren, 1963, p. 176).

This basic tenet is that changes in emotion, reflected in changes in the autonomic nervous system, can be measured as a function of changes in color (hue) and brightness. 
The amount of research which directly supports these statements is limited. The literature which has given rise to these assumptions and has served as a basis for this area of investigation is equally limited. This absence of a significant body of controlled research prompts a review of the available studies.

It is obvious that the hypothesis itself is not new to psychological research. In his early explorations of the galvanic skin response (GSR), Fere (1892) found that one subject produced a marked change in GSR when she was forced to look through a blue glass. Fere's concern was primarily with the variables which produce changes in GSR and he eventually reported changes in GSR as a function of "a change in light" rather than colors themselves, but it is interesting that this research reflects the earliest autonomic nervous system measurements of the effects of either color or intensity of light. It has also been reported (Pressey, 1921) that Fere observed changes in respiration and pulse rates when hysterical subjects were shown a red light.

Early attempts to define the concept of color have indicated that color produces measurable responses and hinted at differential responses for the varfous hues. One such definition by the Optical Society of America in 1922 has found its way repeatedly into the psychological literature:

Color is the general name for all sensations arising from the activity of the retina of the eye and 1 ts attached nervous mechanisms, this 
activity being in nearly every case in the normal individual, a specific response to radiant energy of certain wave-lengths and intensities.... Color can not be reduced to terms of any purely physical conception; it is fundamentally a psychological category (Troland, 1922, p. 528).

The earlier research into psychological aspects of color was concerned with such subjective aspects as individual color preferences. An excellent review of these studies is furnished by Norman \& Scott (1952) who point out the underlying assumption that affective value has been equated, at least semantically, with intended applications in industry and schools as he studied the effects of various hues and intensities but his findings were based on introspection and observational studies, iimited experimental studies of preference, and studies of task performance while his subjects were seated in front of large colored cards. He concluded that there was "almost absurd difference of opinion" in the subjective areas but that if "color does have any fundamental physiological effect...the connection must be of a very general and elementary nature; brightness may stimulate, or red irritate and distract, but more specific effects are hardly to be expected." He found generally that illumination level would positively effect finger tapping rate, problems in multiplication, and continuous reaction tasks but found no effects from hue alone. He did note, however, variable subjective reports of affective changes with various hues. 
Color preference research was refined by Guilford (1931) in seperate evaluations of the three dimensions of color: hue, chroma, and tint. He found that with hue held constant, there was an increase in affective value paralleling increase in chroma or tint, or both together. However, hue was found to be the most important factor in color preference. This research is responsible for the development of the P-U continuum (pleasaritness-unpleasantness) which is still popular in psychological color research today (Smith, 1958;. Guilford's greatest contribution in the area of color research, however, was the experimental control of chroma, tint, and hue.

The study of color preferences was further refined by Eysenck (1941) with findings that there is general agreement between the sexes in their preferences and that a division exists between subjects in preference for saturated or unsaturated colors.

The relationship between color and emotional pattern has been researched in terms of: (a) the effects of color on emotions, and (b) the effect of emotions on color perceptions. Hevner (1934) found that college students described various colors in emotional terms, with red usually described as happy or exciting, and blue described as serere or dignified. Similar associations were noted by Wexner (1954) after asking his subjects to select color samples which depicted eleven "mood-tones" which the experimenter 
supplied. He found red was selected as "exciting-stimulating", blue as "serene-comfortable", orange as "distresseddisturbed-upset", blue was also selected as "tender-soothing."

Colors have also been found to be associated with musical selections (Odbert, Karwoski, \& Eckerson, 1942). These researchers reported that when subjects were'forced to relate colors to music, they gave responses very similar to the responses given by subjects who readily react with vivid visual imagery. They found also that the colors named with a selection were systematically related to the named mood of the selection; and that when tine subjects were asked to name the coilor best fitting the same mood-words, the results were very similar to those obtained with the use of music.

Behavioral correlates of color have also been reported. Smith (1936) observed a quieting effect of blue light on infants. In his work with organic mental patients, Goldstein (1939) found red to be disagreeable, upsetting, exciting, and physically nauseating.

In an experimental study of the effects of red and green surroundings on psychomotor tasks and judgement, Nakshian (1964) found inconclusive results and noted that "there has been a remarkable dearth of scientific studies dealing with this particular color-behavior problem." However, a limited body of research into the physiological 
effects of color has developed in the last 15 years. The studies cited to this point have been concerned with subjective and preferential responses to color, and to a limited extent, the effects of color on gross behavior. They have all carried the underlying assumption that these responses are potentially measurable on a more molecular level or in terms of a particular body system. Several studies have been undertaken to investigate the differential efrects of color on GSR, heart rate, respiration rate, and other autonomic nervous system functions.

In a comparison of red and green hues on GSR, Wilson (1966) found red to be significantly more arousing than green. Wilson presented red and green slides on a screen and measured changes in skin resistance (GSR). Each of his twenty subjects receivad five presentations of green, in a random order. He found that both red and green stimuli produced measurable GSR's and showed evidence of habituation (decrease in magnitude of charıe over trials) and found mean red scores to be consistently higher than mean green scores ( $\mathrm{p} .05$ on a one-tailed sign test). The subjective reports following the experimental session were consistent with the electrodermal evidence; the red was variously described as more stimulating, awakening, attention-drawing, overpowerIng, and lively than the green. Based on his studies of these two colors, Wilson hypothesized that the arousal value of colors might form a U-shaped function within the visible 
wave length. His predicted relationship is presented in Figure 1. It should be noted that this prediction is based on Wilson's research with only two colors (red and green) and that these colors were identified only as being highly saturated but not otherwise designated according to any standard identification system.

FIGURE 1

Arousal Values of Visible Hues (Wilson, 1966)

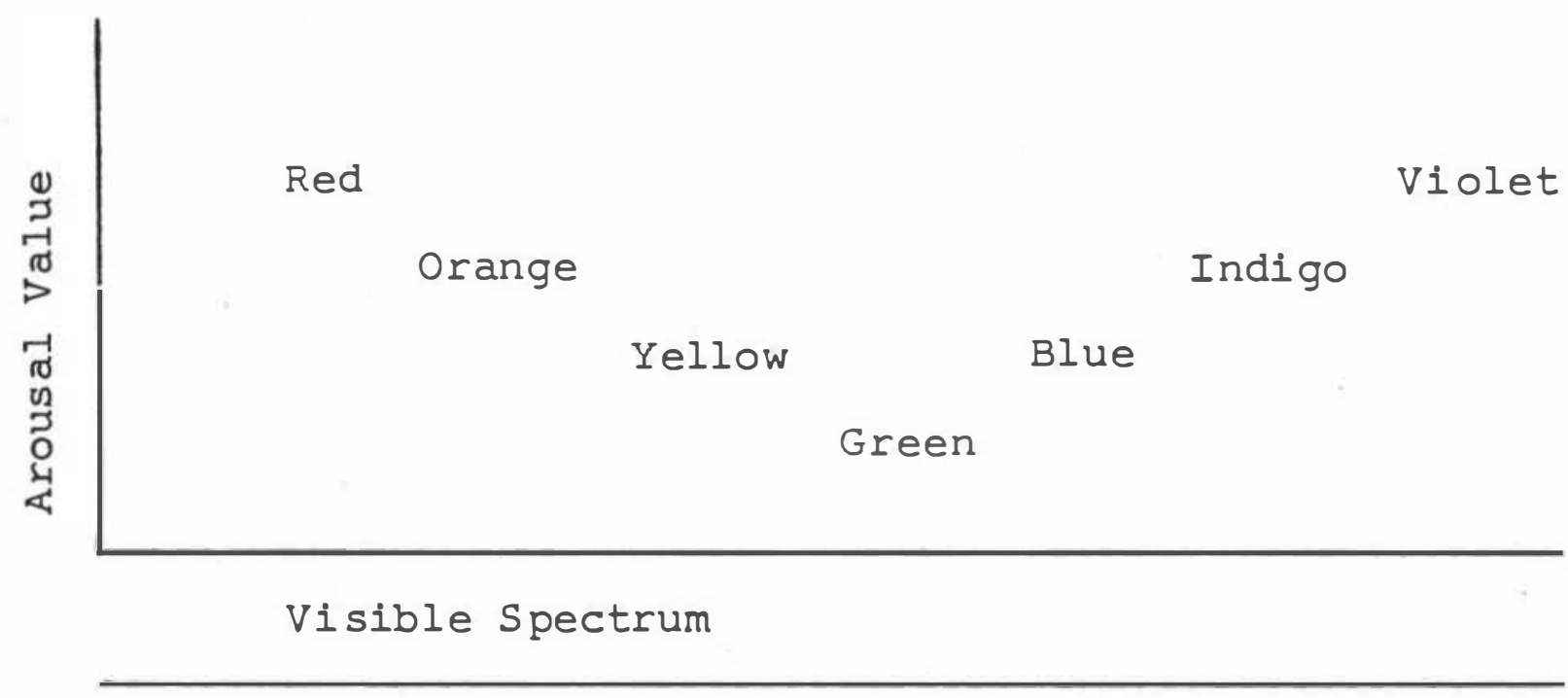

In an attempt to further clarify the relationship hypothesized by Wilson (1966), Nourse \& Welch (1971) studied the GSR as a function of violet and green illumination, using colored bulbs behind a viewing screen. During continuous measurement of electrodermal activity fourteen subjects received either a series of $G V G V G V$ or $V G V G V G$ lights. A significant difference between the green and 
violet conditions was found for the first trial and that difference was found to habituate to insignificant differences on later trials. Nourse \& Welch (1971) concluded that violet was more arousing than green in support of Wilson's (1966) hypothesis. It must be noted however that a spectral analysis of the two light sources showed that the violet condition emitted peak wave lengths at both blue ( $455 \mathrm{~nm}$ ) and red $(677 \mathrm{~nm})$ while the green source produced a peak at green only $(535 \mathrm{~nm})$. It was also found that the two conditions produced different configurations of illumination within the presentation box, a cross and an $x$, due to the placement of the tulbs. It is possible that the differences found were actually differences due to visual configuration or a significant difference between red and green rather than between blue-violet and green, in which case wilson's (1966) hypothesis is not well supported by Nourse \& Welch (1971).

The conclusions which were cited earlier in this paper by Baker (1961) and Birren (1963) were based on research undertaken by Robert Gerard for his unpublished doctoral dissertation in clinical psychology at University of California, Los Angeles (Gerard, 1958a). This research was sumnarized by Gerard at the 69th American Psychological Assoclation convention (Gerard, 1958b) with implications for Rorschach theory, psychodiagnosis, and color therapy. Gerard's methodology included the projection of red, blue, 
and white lights of equal brightness on a screen in front of 24 normal adult males while measuring palmar conductance (GSR), respiration rate, frequency of eye blink, systolic blood pressure, heart rate, and electroencephalographic measures (alpha amplitude and alpha percent). Gerard (1958b) reported that the autonomic riervous system and visual cortex were significantly less aroused during blue than during red or white illumination. Also, the subjective reports from his subjects indicated greater relaxation, less anxiety and hostility, during blue; more tension and excitement during red exposure. The following specific results were found:

1. Using analysis of variance, significant color effects were found with all dependent variables, except heart rate.

2. Systolic blood pressure, palmar skin conductance (GSR), respiration rate, and frequency of eye blinks, were significantly lower during blue than during red or white illumination. Alpha waves from the visual cortex were present for a significantly greater percentage of the time during blue than during white or red conditions, indicating less cortical arousal during blue illumination.

3. In terms of mean change from resting level, red was found to be more arousing than white, and 
white was found to be more arousing than blue, except in terms of alpha amplitude.

In an investigation of the relationship between effects on GSR and subjective reports when subjects were presented with three by five inch color plates, Smith (1958) found that the hues rated high in excitory value produced greater GSR's than the hues rated low in excitory value. This study used the entire ten Munsell hues previously used by Guilford (1931). One criticism of Smith's study is that he eliminated six of his original twenty subjects before analysis of the data on the aposteriori grounds that their GSR changes were insignificant. This had the obvious effect of limiting the generality of his results to those subjects who show GSR, changes. Even though his results are limited, Smith found that the least GSR change was associated with blue, with increasing changes to purple, blue-green, yellowred, red, purple-blue, yellow, green-yellow, red-purple, and the highest GSR change with green. These findings are not in agreement with other studies cited (Gerard, 1958; Wilson, 1966) but may be effected by the procedural error, the colors used as stimuli, or the size of the sample. The effects of color on capillary blood-oxygen saturation have been studied by Doust and Schneider (1955) who used normal and psychiatric patients as subjects. They found that by means of autonomically controlled vasoconstriction all of the seven colors used, except white, lowered the oxygen content of the blood, with the differences being less 
marked for hues at the blue-green end of the spectrum and most apparent with hues at the red end of the spectrum. Significant differences were found between blue and yellow and between blue and green. They also noted that psychiatric patients displayed a lessened reaction to color than the normal subjects.

The absence of a significant effect on heart rate as a function of either red or blue hues in the single study which related heart rate to color (Gerard, 1958) was not expected because heart rate changes have been found in other studies of the autonomic nervolis system in which color was not used as the independent variable. A general autonomic response to environmental stimulation was reported as early as 1922 by Guildmeister (1928) in which he measured changes in pupilary response, vasomotor functions, skin temperature, GSR, and heart rate. This list of dependent variables in the general autcnomic response was expanded by Landis (1930) to include respiration, muscular activity, and changes in the $\mathrm{pH}$ of serum and saliva. While the general autonomic response was not studied specifically as a response to color, these variables are all under control of the autonomic nervous system and have been shown to reflect changes in various psychological processes including visual perception and changes in affective states.

It should also be noted that a wide variety of colors have been used in the studies reviewed and that little 
attention has been paid to the specification of colors. Gerard (1958) made an a priori selection of colors and proceeded to specify these colors as exactly as possible by measurement. Two other researchers who specified their colors (Smith, 1958; Guilford, 1931), have done so according to the Munsell notation and have equated their colors for brightness (Munsell value) and saturation (Munsell chroma). This procedure produced colors which would not normally be described by observers as being red, yellow, green, or blue even though the Munsell notations (5R5/6, 5Y5/6, 5G5/6, 5B5/6) suggest that they approximate these colors. After examining these colors it is easy to suggest that this is a potential source of insignificant results in these studies since the Munsell colors used were neither vivid or strong. It is readily apparent that the studies reviewed do not provide adequate evidence to reliably predict the differential effects of color when these effects $彐 r e$ measured as changes in the autonomic nervous system. Methodological problems and lack of agreement in results have marked the major studies in this area (Gerard, 1958; Smith, 1958; Wilson, 1966). Figure 2 presents a summary of these studies and the effects found. 
FIGURE 2

Summary of Previous Research

\begin{tabular}{|c|c|c|c|}
\hline $\begin{array}{l}\text { Dependent } \\
\text { Variable }\end{array}$ & Source & $\begin{array}{l}\text { Ind ependent } \\
\text { Variable }\end{array}$ & Results \\
\hline \multirow[t]{3}{*}{ GSR } & Gerard (1958) & red, blue, white & $\begin{array}{l}\text { Greater GSR change } \\
\text { with red than blue. } \\
\text { White located be- } \\
\text { tween red and blue } \\
\text { in terms of arou- } \\
\text { sal val:?e. }\end{array}$ \\
\hline & Smith (1958) & ten Munsell hues & $\begin{array}{l}\text { Rank order of } \\
\text { increasing GSR } \\
\text { change for psycho- } \\
\text { logical primaries: } \\
\text { blue, red, yellow, } \\
\text { green. }\end{array}$ \\
\hline & Wilson (1965) & red, green & $\begin{array}{l}\text { Greater GSR change } \\
\text { with red than } \\
\text { green. }\end{array}$ \\
\hline Heart Rate & Gerard (1958) & red, blue, white & $\begin{array}{l}\text { Insignificant } \\
\text { change. }\end{array}$ \\
\hline Ręspiration & Gerard (1958) & red, blue, white & $\begin{array}{l}\text { Respiration in- } \\
\text { creased with red } \\
\text { and decreased with } \\
\text { blue when compared } \\
\text { to white illumin- } \\
\text { ation. }\end{array}$ \\
\hline
\end{tabular}

Even though these results are not completely in agreement, there is evidence presented which suggests that differential color effects exist. Using the four primary psychological colors, there is not enough evioence to predict exact relationships, except red is usually found to be more arousing than the other hues when GSR is used as the dependent 
variable, except in the study by Smith (1958). These studies have generally contrasted one color against another and measured one variable, usually GSR,

Statement of Hypothesis.

This investigation was undertaken to specifically study the differential effects in GSR, heart rate, and respiration rate as a function of the four primary psychological colors. The use of four colors, rather than a study of two colors, was used to provide a better understanding of the relationship between the colors in the visible spectrum. Rather than limit the measurement to one variable, the variables of GSk, heart rate, and respiration rate were selected to provide added evidence and understanding to the study of the effects of color on the humair body.

The following research hypotheses were formulated to study the differential effects of color:

1. The four primary psychological colors will be associated with differential effects in the amplitude of the galvanic skin response (GSR).

2. The four primary psychological colors will be associated with differentizl effects in the heart rate.

3. The four primary psychological colors will be associated with differential effects in the rate of respiration. 
CHAPTER II

EXPERIMENTAL METHODOLOGY

Subjects.

Subjects for this study were 24 male sollege students recruited as unpaid volunteers from undergraduate Psychology classes at Eastern Illinois University. The median age for subjects was 20 years with a range of 17 to 27 years.

Stimuli Colors.

The following method was used to select the four primary psychological colors which served as independent variables in this stuiy. Ten male observers who did not participate in this study were asked to select from the ISCC-NBS Color Names Chart (Inter Society Color Council-National Bureau of Standards, NBS Standard Sample No. 2106) those colors which they considered to be the best examples of red, yellow, green, and blue. Eight of the ten observers unanimously agreed on the colors listed in Figure 3.

\section{FIGURE 3}

Stimuii Colors

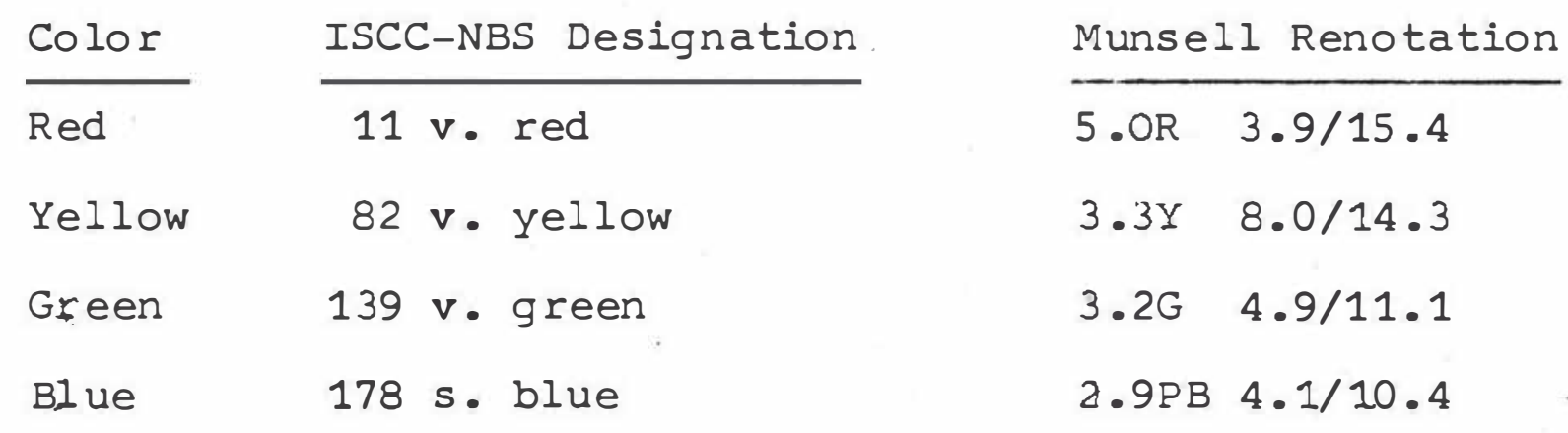


It should be noted that in all cases the observers selected the most saturated colors available in each hue (highest Munsell chroma) which was at least ten steps away from gray on the Munsell notation. A wide variation in brightness (Munsell value) was selected, ranging from Munsell 3.9 for red to 8.0 for yellow. Similar results would be predicted by the research of Granger (1952). The ISCC-NBS designations (Kelly \& Judd, 1955) indicate that the colors selected have been described either as vivid ( $v_{0}$ ) or strong ( $s_{.}$) examples of these colors according to the ISCC-NBS system. These selected colors ware ther obtained from the Munsell Color Corporation as 9 by 12 inch glossy plates. These color plates were photographed on Ektachrome-X 35 millimeter film under artificial lighting balanced to daylight conditions by using an $85 \mathrm{c}$ filter on the camera lens to obtain an accurate exposure.

The stimulus colors which had been reproduced on slides were projected on a 3 by 4 foot projection screen located ten feet in front of the subjects by using a Kodak Carousel projector. A second projector was used to project a white inter-slide interval between coior presentations. A dissolve unit (Kodak, model 2) was used to dissolve between projectors, thereby avoiding the potentially disruptive effect of a slide change on the screen. The actual screen area used for tine projection of the colors and intertrial white was 23 by 33 inches. 
Using the diagonal visual angle formula of Cornsweet (1970), these conditions produced a visual stimulus field of 18 degrees.

To insure that the slides used as stimulus colors produced equal levels of illumination on the screen, a photographic light meter (Sekonic Studio Delux, model L-28c) was used to measure incident light striking the screen.' All colors were found to produce 16 foot candles of illumination. In order to equate the illumination from the projector which was used to present the inter-stimulus condition, a pair of polaroid filters was placed in frort of the projector lense. By independently rotating these filters, it was possible to produce a continucus graduatior of transmission. Using the same procedure as noted above, the second profector was equated with the first profector to produce 16 foot candles of illumination at the screen. After these conditions were reached, no further alterations were made during the experimentation.

Physiological Apparatus.

Physiological measurements were recorded on a four channel physiograph (E \& M Instruments, model DMP-4A) which was located in the experimental room to the right of the subjects. An exosomatic direct current ( 40 microamperes) GSR was measured from the dorsal and ventral surfaces of the middle digit of the right middle fingers using commercially available lead $(\mathrm{Pb})$ electrodes with a surface area of $3 / 4$ by 
1 inch and a standard GSR preamplifier. Heart'rate was monitored by use of a locally manufactured photoplethysmograph (PPG) attached to the left middle or left ring finger depending on which finger best accomodated the apparatus. Previous experience with this equipment (Boyce \& Jacobs, 1972) demonstrated that a reliable measurement of heart rate could be sbtained by these means when a high gain preamplifier (E \& M Instruments) was used in the EMG mode (time constant of 0.03 seconds). Respiration was measured by means of a thermistor located below the right nostril and held in place by attacnment to eye glasses frames from which the lenses had beer: removed. Respiration was therefore recorded as changes in temperature between inhaled and exhaled air (Boyce \& Jacobs, 1972). The thermistor circuit was attached to a second high gain preamplifier used in the EKG mode (time constant of 2.0 seconds).

In an attempt to produce constant conditions during the recording of the physiological measurements, auditory distractions were reduced as much as possible. All experimental sessions were held between 1 PM and 9 PM since this period coincided with the least use of the psychology laboratory. An air conditioner was installed in the experimental room prior to experimentation in an attempt to produce constant temperature conditions. This air conditioner was operated at a constant high speed throughout all experimental sessions to equate auditory level for all subjects and also had the effect of masking extraneous auditory cues. 
The desired temperature effect was not totally achieved since the range in temperature for the experimental room was from 74 to 92 degrees Farenheit with a median temperature of 85 degress Farenheit. However, the temperature for any single session did not vary more than plus or minus one degree sarenheit during the session. This temperature range would not be expected to effect the results as long as the variation is limited within each experimental session.

\section{Procedure.}

To preclude the possibility of defective color vision, each subject was pre-tested for color vision using Dverine Pseudoisochromatic Plates (Dverine, 1963a). Each subject was required to identify correctly at least 13 of the 14 plates in the Dverine test series, even though this criterion is more rigid than required in other applications of this test (Dvorine, 1963b). This test was necessary ince approximately $8 \%$ of the males in the United States have some form of congenital color blindness (Judd \& Wyszecki, 1963).

$$
\text { Color vision testing was accomplished immediately }
$$

upon arrival of the subject in the experimental room. The experimental room was a 12 by 15 foot research room which contained a reclining type chair, the screen, the air conditioner, a table with physiograph and tape recorder, and a thermometer for recording room temperature. The preamplifiers and Dverine tests were located on a small table adjacent to the subjects' chair. The thermometer was located on 
the wall farthest from the air conditioner and closest to the subject. The projection apparatus was located in a closet behind the subjects and was situated so as to project onto the screen from above and to the subjects' left. Following the color vision tests, subjects were seated and standard instructions were presented by tape recording. These instructions indicated that the purpose of the investigation was to see what effects various kinds of pictures have on the nervous system. They were asked to relax for ten minutes, after which time their basal measurements would be taken, and ihen the study would begin. They were instructec to relax, avoid talking, and avoid moving after the apparatus was connected. The subjects were informed that colors would be presented so that they had something to look at during the basal measurements but were not instructed to respond to the colors. These instructions were designed to disguise the true nature of the study even though previous investigators did not feel this was necessary (Gerard, 1958; Wilson, 1966). The instructions given are included in Appendix $I$.

Each subject was connected to the apparatus at the end of the tape recorded phase of the instructions. General room illumination was accomplished by a covered sixty watt bulb located on the ceiling and remained at this low level throughout the experimental sessions. The screen was illuminated with the inter-stimulus white when the subject entered the room and did not change to a color until after the 
apparatus had been connected, calibrated, and the subject had remained resting in the chair for 10 minutes. This delay was used as a further control to allow the subjects' heart rate, GSR, and respiration to return to a normal resting level prior to experimentation. After this ten minute delay, the experimenter quietly announced that he was now ready to obtain the basal rate.

Each color was presented one time to each subject, for one minute, followed by non-colored illumination for one minute during the inter-trial interval. Four sequences of color presentations were used to insure that each color appeared an equal number of times in each position. Each experimental subject was assigned to a color sequence in the order of his appearance at the laboratory. In this way one fourth of the subjects randomly received each sequence of color presentation. The four color sequences are noted in Figure 4 . 


$$
\begin{gathered}
\text { FIGURE } 4 \\
\text { Order of Stimulus Presentations }
\end{gathered}
$$

$\begin{array}{cllll}\text { Time } & \begin{array}{c}\text { Sequence } \\ 1\end{array} & \begin{array}{c}\text { Sequence } \\ 2\end{array} & \begin{array}{c}\text { Sequence } \\ 3\end{array} & \begin{array}{c}\text { Sequence } \\ 4\end{array} \\ 10 & \text { White } & \text { White } & \text { White } & \text { White } \\ 1 & \text { Red } & \text { Blue } & \text { Green } & \text { Yellow } \\ 1 & \text { White } & \text { White } & \text { White } & \text { White } \\ 1 & \text { Blue } & \text { Yellow } & \text { Red } & \text { Green } \\ 1 & \text { White } & \text { White } & \text { White } & \text { White } \\ 1 & \text { Green } & \text { Red } & \text { Yellow } & \text { Blue } \\ 1 & \text { White } & \text { White } & \text { White } & \text { White } \\ 1 & \text { Yellow } & \text { Green } & \text { Blue } & \text { Red } \\ 1 & \text { White } & \text { White } & \text { White } & \text { White } \\ 1 & \text { NVS* } & \text { NVS* } & \text { NVS* } & \text { NVS* } \\ & \text { White } & \text { White } & \text { White } & \text { White } \\ & & & & \end{array}$

These color sequences were randomly determined as was required by the latin square design (Edwards, 1968; Myers, 1966). 
FIGURE 5

Latin Square

Original Latin Square

A $\quad$ B $\quad$ C $\quad$ D

(Edwards, 1968)

B D A $C$

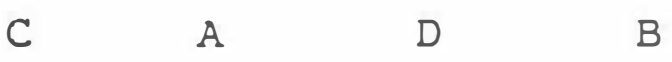

D $\quad$ C $\quad B \quad A{ }^{\circ}$

Assignment of Colors

to Treatment Groups

$\begin{array}{lllll}\text { Sequence } 1 & \text { Red } & \text { Blue } & \text { Green } & \text { Yellow } \\ \text { Sequence 2 } & \text { Blue } & \text { Yellow } & \text { Red } & \text { Green } \\ \text { Sequence 3 } & \text { Green } & \text { Red } & \text { Yellow } & \text { Blue } \\ \text { Sequence 4 } & \text { Yellow Green } & \text { Blue } & \text { Red }\end{array}$

A novel visual stimulus which was unrelated to the stimulus colcrs was inserted following the presentations of all colors. This was done to insure that recording apparatus was operative in the event that the GSR or other measured demonstrated complete habituation as the result of the repeated trials.

Each slide change was recorded on the event channel of the physiography by connecting both the slide change control and the physiograph event marker to an external switch which was activated mannually by the experimenter at one minute intervals. 


\section{CHAPTER III}

\section{RESULTS}

The GSR was defined as the maximum change in skin resistance which occured during the first 15 seconds following presentation of each stimulus color. This change was converted to a log conductance measure (the logarithm to the base ten of the reciprocal of the resistance) prior to statistical analysis of the data. To facizitate the analysis of the data, the conductance was multiplied by 100 prior to log transformation to eliminate unnecessary zeros. To eliminate the infinitely negative logarithm which would have resulted from a log transformation of a zero resistance change, one ohm resistance was added to the resistances of all scores prior to obtaining conductance. This procedure was recommended by Edwards (1950) as the best method of obtaining meaningful logarithms when the original data contains zeros. The effect obtained was a logarithm of zero when the original resistance change was zero. While these procedures do not produce strict log conductance measurements they have teen recommended and used by Nichols \& Daroge (1955). Previous research (Haggard, 1949; Keuchenmeister, 1970; Nichols \& Darogue, 1955; Schlosberg \& Stanley, 1953) suggests that a log conductance measure is the best measure for quantification of GSR data since it provides: additivity (equal interval data), normality (scores which are normally distributed), homogeneity of variance (common 
variances for variables and error estimates), and independence of means and variances (variances are unaffected by changes in the mean).

Heart rate measurements were made during the first 30 seconds following the presentation of the color and were transformed to obtain a beat per minute rate by multiplying these measurements by two. Respiration rates were also transformed from the first 30 seconds after presentation of the stimulus colors to obtain a cycles per minute rate. Similar measurements for heart rate and respiration rate were made during the last 30 seconds of the inter-stimulus conditicr. To study the actual affects of the colors, the data analysis was conducted on the difference between the pre-stimulus condition and the color condition. This data met the requirements for analysis of variance without further transformation. However, to eliminate the necessity of analyzing negative as well as positive changes, a constant of 20 units was added to each difference figure. This procedure is consistent with the recommendation of Edwards (

To provide a statistical test of the formal hypotheses, a latin square analysis of variance was employed (Edwards, 1968; Myers, 1966). This latin square is shown in figure 5. The replicated 4 by 4 latin square was selected as the appropriate statistic to test the effects of color, the order of presentation, and the variance attributable to subjects. With each subject receiving one of the 
four sequences of stimulus presentations (treatments) noted in figures 4 and 5 , each latin square accomodated four subjects. The same latin square was replicated five additional times to accomodate the twenty-four subjects in this study. This procedure produced an error term with more than 30 degrees of freedom and increased the liklihood that significant treatment differences would be declared significant (Edwards, 1968). A significance level of .05 was established prior to analysis of the data as the level required to confirm each hypothesis. Ihis procedure was repeated using the same latin square design for each of the dependent variables (GSR, hezrt rate, and respiration). The result of this procedure produced a seperate analysis of variance for GSR, heart rate, and respiration to test each of the respective hypotheses.

The analyses of the effects of the four colors on GSR, heart rate, and respiration rate are summarized in Table 1 , with analysis of variance tables for each dependent variable included as Appendix II.

\section{TA.BLE 1}

Summary of Physiological Changes

( $F$ ratios)

\begin{tabular}{l|l|l}
\hline \hline Measure & Color & Column \\
\hline GSR & $3.359 *$ & 2.491 \\
Heart Rate & 0.263 & 0.344 \\
Respiration Rate & 1.606 & $3.286^{*}$ \\
\hline
\end{tabular}

$* p<.05$ 
The four primary psychological colors were found to be associated with differential effects in amplitude of GSR. The effects of trials (columns) for GSR was not significant indicating that there was no significant change in the response across trials as might be expected due to habituation or fatigue.

The nature of the differential color effects on GSR are presented in Figure 6 . It is apparent that the most arousing color was red, followed by green and yellow, with blue being the least arousing of the four colors.

FIGURE 6

Arousal Values (Conductance) of Four Colors

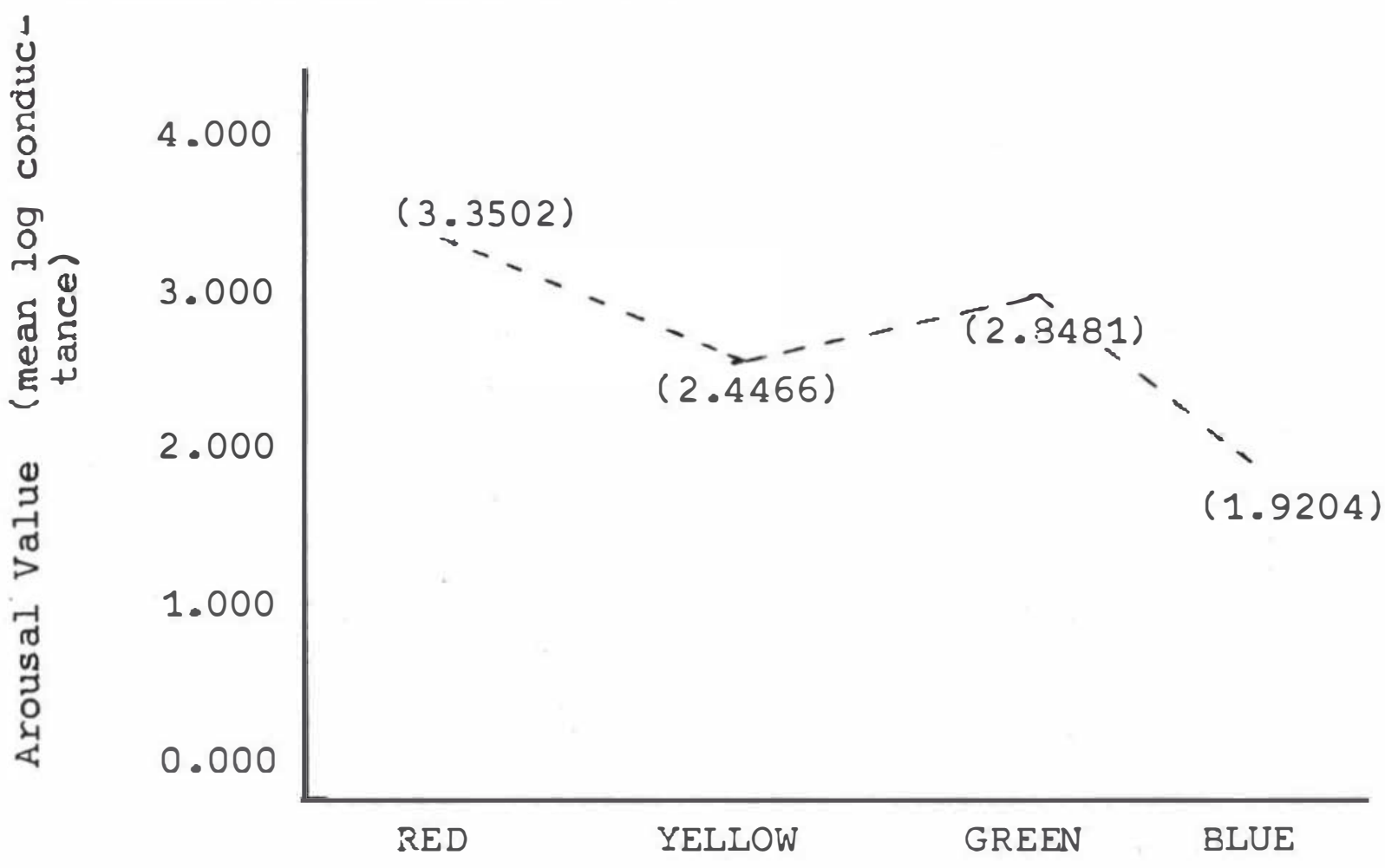

To test the significance of the differences between arousal values obtained, a series of t tests (two tail) for correlated 
data was employed using 23 degrees of freedom.' Significant differences at or exceeding the .05 level were obtained between red-blue, green-blue, and yellow-red. Other differences were not significant on a two tail t test. Using a one tail test the differences between red-green and yellowblue were significant at the .05 level. This data is presented for informational purposes in Table 2 .

TABLE 2

Difference in Arousal Value of the Four Colors

\begin{tabular}{l|c|c|c}
\hline Color Combination & $\begin{array}{c}\text { Difference } \\
\text { (Mean log C) }\end{array}$ & t ratio & $\begin{array}{c}\text { Level of } \\
\text { Significance }\end{array}$ \\
\hline Red - Blue & 1.4297 & 5.31 & .005 \\
Green - Blue & 0.9277 & 3.0627 & .01 \\
Red - Yellow & 0.9135 & 2.4141 & .05 \\
Yellow - Blue & 0.5262 & 1.7682 & .10 \\
Red - Green & 0.5021 & 1.8180 & .10 \\
Green - Yellow & 0.4015 & 1.7074 & NS \\
\hline
\end{tabular}

All comparisons based on 23 degrees cf freedom.

The analysis of the effects of color on heart rate does not support a differential color effect in that system. Neither the effects of color nor the effects of columns was significant, suggesting that heart rate changes are independent of experimental effects under the conditions investigated.

The analysis of the effects of color associated with changes in respiration rate showed insignificant color effects. The significance of the column effect suggests that 
a relationship exists across trials without regard to the colors presented. These trial effects, disregarding color, are presented in Figure 7.

\section{FIGURE 7}

Changes in Respiration Rate by Trial

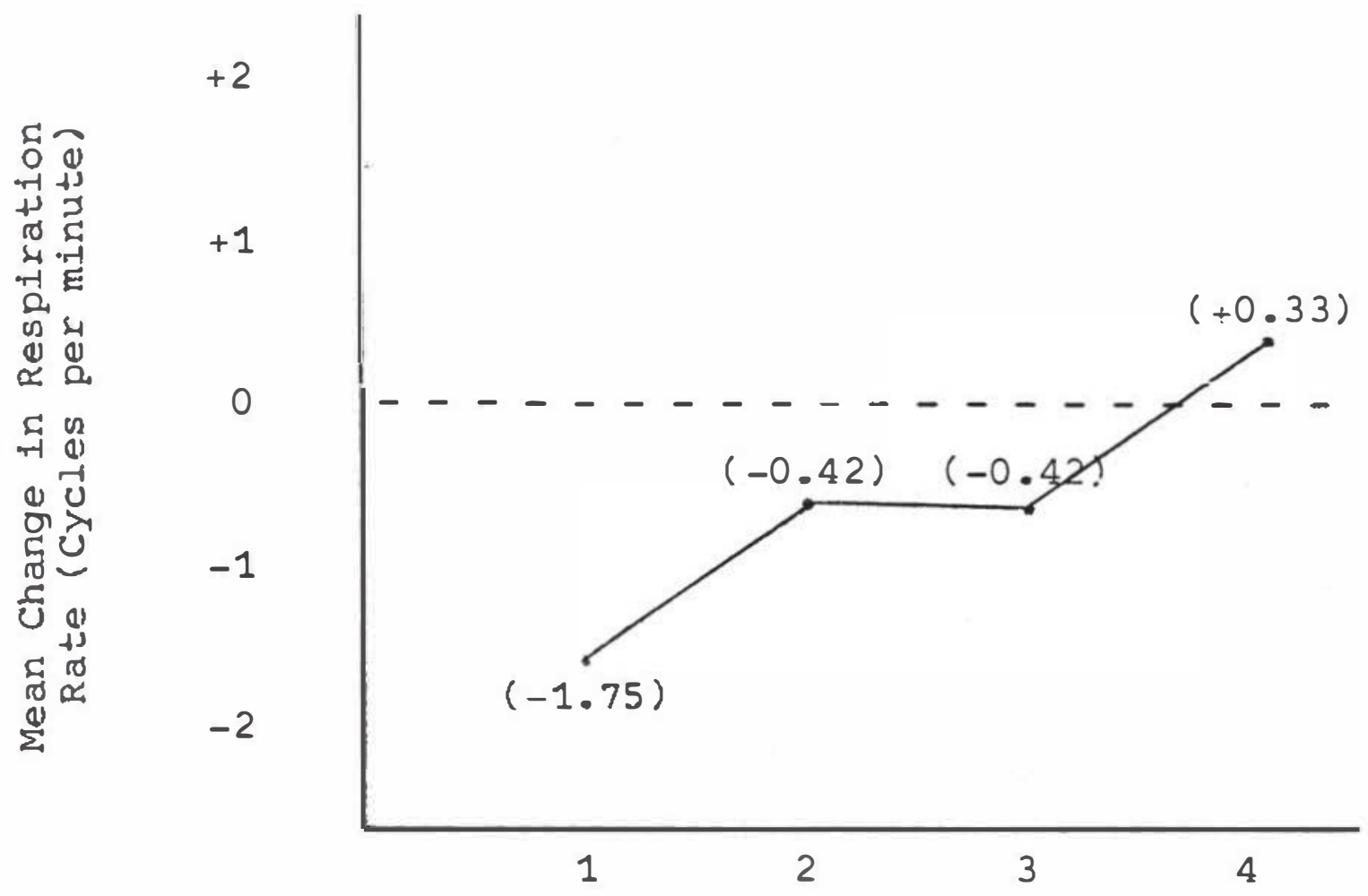

It is apparent that the initial stimulus was associated with a mean reduction in rate of respiration $(-1.75$ cycles per minute), with minimal reductions on the second and third trials ( $-0.42 \mathrm{cpm})$, and a mean increase in respiration rate $(+0.33 \mathrm{cpm})$ on the fourth stimulus. 
CHAPTER IV

DISCUSSION

Color Effects.

The hypothesized differential color effects were found to be significant for the GSR, with changes in heart rate and respiration being insignificant. The strict interpretation of these findings must therefore be that the four primary psychological colors used in this study are associated with differential effects in the galvanic skin responses (GSR's) which are elicited with the introduction of the stimulus colors, and that comparable shanges in heart rate and respiration rate were not found in this study.

It should be noted that the popularity of the GSR in psychological research is partially due to its sensitivity as a dependent variable. Heart rate and respiration rate have received considerably less attention since they are less responsive measures. This research does not establish that comparable changes in heart rate and respiration rate do not exist, but only that these effects were not found linder the conditions used in this study.

The relationship found between red and blue is consistent with several previous studies (Gerard, 1958; Wilson, 1966) in which red has been found to be more arousing than blue. With the high arousal attributed to red and a low arousal attributed to blue, at the distant end of the visible spectrum, it might have been hypothesized that a fairly 
linear relationship exists between arousal value and wave length in which the most arousing color is red, with decreasing arousal for yellow, green, and blue. As was noted in Figure 6, such a relationship was not found in this study since green was found to be more arrousing tinan yellow. Even though the linearity of this relationship can not be investigated empirically from this study since the spectral values of the colors are not known exactly, it is obvious that arousal value is not a linear function of wave length, especially with significant differences established between each of the colors.

The finuing by Gerard (1958) that red was more arousing than blue has been supported in this research. The nonlinear U-shaped relationship between arousal values and wave length (Figure 1) hypothesized by Wilson (1966) is not supported by this study. Wilson's hypothesis was developed from a study of only two colors and was extrapolated to include the remainder of the visible spectrum. It should be noted that the significant difference that Wilson found between red and green, as well as the higher arousal value for red than green, is supported.

In a comparison with the study by Smith (1958), the present results are not in agreement. Smith's arousal values produced a scatter across the visible spectrum but show green to be most arousing, followed by yellow and red, with blue the least arousing of the colors which were used in both studies. The individual relationships between red and blue 
and between green and yellow are confirmed in this study but the overall relationships between the colors are not comparable. These differences may be attributed to the colors used by Smith (unsaturated and equated), to his methodology, or may be true when only those who respond to color are used in the analysis.

It is difficult to relate the findings of Nourse \& Welch (1971) to the present study since their colors were green and purple, only one of which was used in this study, and their purple contained components of red and blue. Their findings that purple is more arousing than green is supported only for the red component of purple with conflicting findings for the relationship between blue and green. The results of the present study support the criticism that the higher arousal value found by Nourse \& Welch for purple than green is actually a higher arousal value for red than blue.

The lack of a significant color effect on heart rate is consistent with the single study which used heart rate as the dependent variable for color (Gerard, 1958). The lack of a significant effect on respiration however, disagrees with the significant color effect obtained by Gerard (1958). This difference may be partially explained in that Gerard used longer periods of color presentation and several presentations of each color. In contrast, this study sought to investigate the initial effects of the colors which are associated with changes in respiration following a single 
presentation of each color. It is possible that respiration effects do not occur initially in the organism but require long exposure to the color.

Response Habituation.

It is well known that the responses to repeated presentations of a stimulus habituate, that is the responses diminish with repetition of the stimulus. In an investigation of the cicienting response (OR), Lynn (1966) reported total habituation (to extinction) of the GSR after seven or eight presentations of an auditory stimulus, with complete habituation of the $O R$ in all systems measured by 10 to 30 repetitions of the same stimulus.

Again disregarding color effects, the habituation to repeated stimulus presentations is presented in Table 3 along with the recovery of the response when the novel visual stimulus is presented. In the interpretation of these results it must be noted that the inter-trial intervals between each tabled value represents a white stimulus. Therefore, the habituation to the second color is the habituation to the third visual stimulus. It should also be noted that this table presents the percent of subjects showing total habituation (to extinction) not merely decrements in magnitude of response as well as subjects showing no response on àny trial. 
TABLE 3

Response Habituation

Habituation to Extinction by Trial

(Percent of subjects showing no response)

\begin{tabular}{l|c|c|c|c|c}
\hline & Color 1 & Color 2 & Color 3 & Color 4 & $\begin{array}{l}\text { Novel } \\
\text { Visual } \\
\text { Stimulus }\end{array}$ \\
\hline GSR & $13 \%$ & $20 \%$ & $33 \%$ & $30 \%$ & $8 \%$ \\
Respiration & $25 \%$ & $54 \%$ & $50 \%$ & $54 \%$ & $42 \%$ \\
Heart Rate & $38 \%$ & $25 \%$ & $25 \%$ & $50 \%$ & $42 \%$ \\
\hline
\end{tabular}

One of the implications for this data is that if a response is absent in a significant percertage of the subjects due to early habituation, it becomes extremely difficult to reach significance in the results. The habituation of respiration and heart rate responses very likely contributed to the lack of significance in the results obtained in this study, since respiration rate changes become habituated to extinction for $50 \%$ of the subjects by the second color and heart rate changes reach this criterion by the fourth color.

Response System Specificity.

Recent research has shown that a biological response does not necessarily occur in all systems to the same external stimulation. In a typical investigation of the 
orienting response (OR) by Voronin \& Sokolov (1960), 100 human subjects were subjected to a 1000 cycle tone, with OR's observed as EEG changes in 95 subjects, respiration rate changes in 63 subjects, eye movements in 42 subjects, GSR's in 95 subjects, and only 11 subjects showed responses in all of these systems. Comparable results were obtained by Voronin, Sokolov, \& Bao-Khua (1959) in which the first presentation of a $55 \mathrm{db}$ tone elicited the OR in GSR for $95 \%$ of their subjects.

These findings are in agreement with the general patterns of physiological activation which have been investigated by Lace $\ddot{y}$ and others (Lacey: 1950; Lacey, Bateman, \& Van Lehn, 1953; Lacey \& lacey, 1958; Schnore, 1959; McNulty \& Noseworthy, 1966). Marked individual differences have been reported between subjects with respect to which physiological measures show the greatest change under standard conditions of stimulation. These authors have also agreed that the patterns of physiological activation are relatively consistent across qualitatively different situations for any particular individual.

When the results of this study are viewed in terms of response system specificity, comparable results are found. Table 4 presents the number and percent of subjects responding to the first trial of color and to the novel visual stimulus. It is apparent that the most responsive dependent variable is GSR, with heart rate as the least responsive 
system. The presence of heart rate changes in only sixtytwo percent of the total subjects may be assumed to have contributed to the lack of significant color effects for heart rate. The inclusion in the data of measures from non-responsive systems may contribute to the lack of significance as noted by McNulty \& Noseworthy (1966) and is especially relevant to this study of respiration and heart rate.

TABLE 4

Response System Specificity

\begin{tabular}{|c|c|c|c|c|}
\hline \multirow[b]{2}{*}{$\begin{array}{l}\text { Dependent } \\
\text { Variable }\end{array}$} & \multicolumn{2}{|c|}{ Response to 1st color } & \multicolumn{2}{|c|}{$\begin{array}{l}\text { Response to Novel } \\
\text { Visual Stimulus }\end{array}$} \\
\hline & $\begin{array}{l}\text { Number of } \\
\text { Subjects } \\
\text { Responding }\end{array}$ & $\begin{array}{l}\text { Percent of } \\
\text { Subjects } \\
\text { Responding }\end{array}$ & $\begin{array}{l}\text { Number of } \\
\text { Subjects } \\
\text { Responding }\end{array}$ & $\begin{array}{l}\text { Percent of } \\
\text { Subjects } \\
\text { Responding }\end{array}$ \\
\hline GSR & 21 & $88 \%$ & 22 & $92 \%$ \\
\hline Respiration & 18 & $75 \%$ & 14 & $58 \%$ \\
\hline Heart Rate & 15 & $62 \%$ & 14 & $58 \%$ \\
\hline
\end{tabular}

The appearance of the results at this point would suggest that differential color effects mignt be associated with changes in heart rate and resporation rate for those subjects who consistently respond in these two systems. However, since this hypothesis was not a part of the original design, the statistical procedures used do not lend themselves to this investigation. By eliminating non-responding 
subjects from the data for each system the subjects would no longer be randomly assigned to treatment groups and the latin square would no longer be complete.

Suggestions for Further Pesearch.

The next logical question to be asked after the analysis of the results for this study is whether those subjects who respond in terms of heart rate and respiration rate should show diffarential color responses in those systems. This would require increasing the total number of subjects and eliminating those who do not respond in the system being measured. Even though this procedure is not consistent with the latin square statistic used in this study, a repeated measures analysis of variance may be used or a large number of subjects who have been shown to respond in the system may be independently assigned to different color groups to allow analysis of independent measures. The measurements of heart rate and respiration rate may also be made more sophisticated and accurate by use of commercially avail able apperatus designed for precise measurements such as beat to beat heart rate.

Expansion of the dependent variables which are associated with color effects is also needed. In addition to more extensive studies of heart rate and respiration rate changes, more studies are needed in blood pressure, blink rate, EEG changes, EMG activity, and capillary oxygen content, since no more than one study has been located which 
reports the effects of color on each of these variables. The results of this study also suggested that colors might be associated with changes in vasomotor functions. A digital vasomotor measuring device (photo-plethysmograph) was used in this study for convenience in measuring heart rate with no attempt to establish accurate vasomotor measurements since the a priori conclusion was made that precise measurements of vasocongestion and vasodilation would not be obtained with this apparatus. Another question raised by this study is whether the colors would be associated with differential erfects in the occurance of spontaneous skin potential responses. This area has not been investigated previously and such effects might well be found under prolonged exposure to various colors.

The present line of research using more than two colors to study the relationships between the colors in physiological effects definately deserves more experimental investigation. The studies reported in the literature which have compared two colors and extrapolated from them to other hues in the visible spectrum are necessarily limited by the use of two colors. The use of four colors in this study is not intended to provide definitive results across the visible spectrum but only to take one step in that direction.

A further criticism of previous research has been that only two investigators (Guilford, 1931; Smith, 1958) have used identical colors or even the same procedure for obtaining the stimulus colors. Oily one investigator has 
fully specified the spectral characteristics of his colors (Gerard, 1958) and few others have reported the peak transmission wave lengths of their colors (Nourse \& Welch, 1971). If the results of one study are to be accurately compared with another study it is imperative that the colors be identical in terms of hue, saturation, tint, and intensity of presentation. The specification of the colors also facilitates the investigation of the relationship between colors and wave length when several colors are used in the same study. 
KEFERENCES

Baker, S. Visual persuasion. New York: McGraw-Hill, 1961.

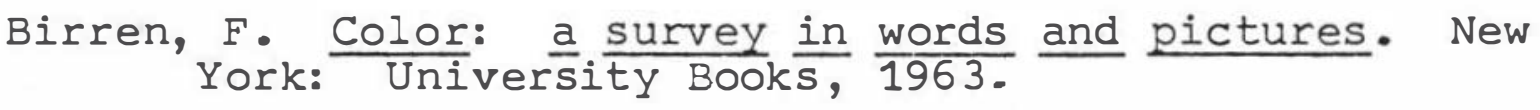

Boyce, L. \& Jacobs, K. Voluntary control of GSR using continuous visual display with simultaneous changes in heart rate and respiration. Unpublished research, Eastern Illinois University: 1972 .

Cornsweet, T. N. Visual perception. New York: Academic Press, 1970 .

Doust, J. W. \& Schneider, R. A. Studies on the physiology of awareness: the differential influence of color on capillary blood-oxygen saturation. Journal of Clinical Psychology, 1955, 11, 366-370.

Dvorine, I. Dvorine psuedo-isochromatic plates. New York: Harcourt, Brace, and world, 1963a.

Dvorine, I. Quantatative classification of the color-blind. Journal of General Psychology, 1963b, 68, 255-265.

Edwards, A. L. Experimental design in psychological research. New York: Holt, Rinehart, and Winston, 1950.

Edwards, A. L. Experimental design in psychological research. ( 3 rd ed.) New York: Holt, Rinehart, and Winston, 1968 .

Eysenck, H. J. A critical and experimental study of color preferences. American Journal of Psychology, 1941, $54,385-394$.

Fere, C. La pathologie des emotions. Paris: Alcan, 1892. Cited by C. Landis. Psychology and the psyahogalvanic reflex. Psychological Review, 1930, 37, 381-398.

Gerard, R. Differential effects of colored lights on psychophysiological functions. Unpublished doctoral dissertation, University of California, Los Angeles, 1958 .

Gerard, R. Color and emotional arousal. American Psychologist, 1958, 13(7), 340. (Summary)

Guildmeister, M. Handbook of normal and pathological physiology, $1928,8,657-702,766-784$. 
Goldstein, K. The organism. New York: American Book, 1939.

Goldstein, K. Some experimental observations concerning the influences of colors on the functions of the organism. Occupational Therapy, 1942, 21, 147-151.

Granger, G. W. Objectivity of color preferences . Nature, $1952,170,788-780$.

Guilford, J. P. The prediction of affective value. American Journal of Psychology, 1931, 43, 469-478.

Haggard, E. A. On the application of analysis of variance to GSR data: I the selection of an appropriate measure. Journal of Experimental Psychology, 1949, $39,378-392$.

Hevner, K. Experimental studies of the affective value of colors and lines. Journal of Applied Psychology, $1935,19,385-398$.

Inter Society Color Councjl \& National Bureau of Standards. ISCC-iJBS Centroid Color Charts. (NBS Standard Sample No. 2106) Washington, D.C.: 'National Bureau of Standards, nd.

Judd, D. B. \& Wyszecki, G. Color ir business, science, and industry. New York: Wiley and Sons, 1963.

Kelly, K. L. \& Judd, D. B. The ISCC-NBS method of designating colors and a dictionary of color names. (National Bureau of Standards Circular 553) Washington, D.C.: National Bureau of Standards, 1955.

Keuchenmeister, C. A. Instrument for direct readout of log conductance $(\log 1 / R)$ measures of the galvanic skin response. Psychophysiology, 1970, 7(1), 128-134.

Lacey, J. I. Individual differences in somatic response patterns. Journal of Comparative and Physiological Psychology, $1950,43,338-350$.

Lacey, J. I., Bateman, D. E., \& Van Lehn, R. E. Autonomic response specificity: an experimental study. Psychosomatic Medicine, 1953, 15, 8-21.

Lacey, J. I. \& Lэcey, B. C. Verification ard extension of the principle of autonomic response stereotypy. American Journal of Psychology, 1958, 71, 50-73.

Lynn, R. Attention, arousal
New $\frac{\text { and }}{\text { York: Pergamon, } 1966}$ the orientation reaction. 
Landis, C. psychology and the psychogalvanic reflex. Psychological Review, 1930, 37, 128-134.

Myers, J. L. Fundamentals of experimental design. Boston: Allyn and Bacon, 1966 .

McNulty, J.A. \& Noseworthy, W. J. Physiological response specificity, arousal, and task performance. Perceptual and Motor Skills, 1966, 23, 987-936.

Nakshian, J.S. The effects of red and green surroundings on behavior. Journal of General Psychology, 1964, $70,143-161$.

Nichols, R. C. \& Daroge, T. An electronic circuit for the measurement of the galvanic skin response. American Journal of Psychology, 1955, 68, 455-461.

Norman, R. D. \& Scott, W. A. Color and effect: a review and semantic evaluation. Journal of General Psycho-

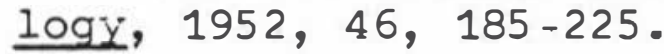

Nourse, J. C. ․ Welch, R. B. Emotional attributes of color: a comparison of violet and green. Perceptual and Motor Skills, 1971, 32, 403-406.

Odbert, H. S., Karwoski, T. F., \& Eckerson, A. B. Studies in synesthetic thinking: I. musical and verbal associations of color and mood. journal of General Psychology, 1942, 26, 153-173.

Pressy, S. L. The influence of color upon mental and motor efficiency. American Journal of Psychology, 1921, $32,326-356$.

Schlosberg, H. \& Stanley, W. A simple test of the normality of twenty-four distributions of electrical skin conductance. Science, 1953, 117, 35-37.

Schnore, M. M. Individual patterns of physiological activity as a function of task differences and degree of arousal. Journal of Experimental Psychology, 1959, $58,117-128$.

Smith, R. S. An investigation of the relationship between physiological and cognitive measures of the affective response to color. (Doctoral dissertation, University of Pennsylvania) Ann Arbor, Michigan: University Microfilms, 1950 . 
Smith, J. M. The relative brightness values of three hues for newborn babies. University of Iowa studies of Infant Behavior III, 1936, 12(1).

Sokolov, E. M. Higher nervous functioning: the orienting reflex. Annual Review of Physiology, 1963, 25, $545-580$.

Troland, L. T. Report of committee on Colimetry. Journal of the optical Society of America, 1922, 6, 527-596.

Voronin, L. G. \& Sokolov, E. N. Cortical mechanisms of the orienting reflex and its relation to the conditioned reflex. In H. H. Jasper \& G. D. Smirnov (Eds.) Moscow colloquium on electroencephalography of higher nervous activity. EEG Clinical Neurophysiology, 1960, Suppl. 13.

Voronin, L. G., Sokolov, E. N., \& Bao-Knua, U. Type features of the orienting reaction in man. Voprosy Psikhologii, 1959, 5, 73-78. Cited by R. Lynn, Attention, Arousal and the orientation Reartion. New York: $\overline{\text { Pergamon, } 1966 .}$

Wexner, L. B. The degree to which colors (hues) are associated with mood-tones. Journal of Applied Psychology, 1954, 38(6), 432-435.

Wilson, G. D. Arousal properties of red versus green. Perceptual and Motor Skills, 1966, 23, 947-949. 
Appendices 
Appendix I

Instructions 


\section{INSTRUCTIONS}

"This experiment is designed to study the effects on the nervous system of various kinds of pictures. The scenes have been selected from great paintings for their variety of subject matter. Each picture will be on the screen for two minutes. All you have to do is sit quietly and do not say anything until the experiment is concluded. It will require a few minutes for me to connect the apparatus and obtain you basal rates before we begin. While I am obtaining the basal measurements please relax and do not talk; I will project some colors on the screen so you have something to look at. Do you have any questions?"

(Experimenter connects apparatus.)

"Please remain calm a few minutes to allow your heart rate to return to its resting lavel and for my equipment to stabilize."

(Following a ten minute pause, the remainder of the instructions are presented verbally without the use of tape recorder.)

"Now I would like to obtain the basal measurements. Please watch the screen and do not talk or move around." 
Appendix II

Analysis of Variance Tables 
Analysis of Variance: GSR

\begin{tabular}{|c|c|c|c|c|c|}
\hline Source & $d f$ & SS & MS & $F$ & Significance \\
\hline Total & 95 & 222,6315 & & & \\
\hline Between & 23 & 105.7764 & & & \\
\hline $\mathrm{R}$ & 3 & 2.0517 & 0.6839 & 0.1319 & \\
\hline$S / R$ & 20 & 103.7247 & 5.1862 & & \\
\hline Within & 72 & 116.8551 & & & \\
\hline Color & 3 & 14.0933 & 4.6978 & 3.3590 & $\mathrm{p}<.05$ \\
\hline Colums & 3 & 10.4530 & $3.484 ?$ & 2.4913 & $\mathrm{p}<.10$ \\
\hline Error & 66 & 92.3089 & 1.3986 & 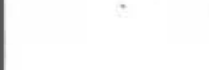 & \\
\hline
\end{tabular}

$\mathrm{p}=$ the probability that an $\mathrm{F}$ ratio as large as the obtained $F$ ratio could have occurred by chance alone. 
Analysis of Variance: Heart Rate

\begin{tabular}{c|r|r|r|l|l}
\hline \hline Source & df & SS & MS & F & Significance \\
\hline Total & 95 & 1714.5 & & & \\
Between & 23 & 304.5 & & & \\
R & 3 & 70.833 & 23.611 & 2.021 & \\
S/R & 20 & 233.667 & 11.683 & & \\
Within & 72 & 1410.0 & & & \\
Color & 3 & 13.833 & 4.611 & 0.263 & \\
Column & 3 & 18.167 & 6.056 & 0.344 & \\
S U & 6 & 324.167 & 54.028 & 3.076 & p $<.01$ \\
Residual & 60 & 1053.833 & 17.564 & & \\
\hline
\end{tabular}

$\mathrm{p}=$ the probability that an $\mathrm{F}$ ratio as large as the obtained $F$ ratio could have occurred by chance alone. 
Analysis of Variance: Respiration Rate

\begin{tabular}{c|r|r|r|l|l}
\hline \hline Source & df & SS & MS & F & Significance \\
\hline Total & 95 & 685.625 & & & \\
Between & 23 & 242.625 & & & \\
R & 3 & 5.125 & 1.708 & 0.144 & \\
S/R & 20 & 237.500 & 11.875 & & \\
Within & 72 & 443.000 & & & \\
Color & 3 & 26.458 & 8.819 & 1.606 & \\
Column & 3 & 54.125 & 18.042 & 3.286 & pi.ū \\
Error & 66 & 362.417 & 5.491 & & \\
\hline
\end{tabular}

$\mathrm{p}=$ the probability that an $\mathrm{F}$ ratio as large as the obtained $F$ ratio could have occurred by chance alone. 
Appendix III

Original Data 
Original Data: GSR

(Expressed in log conductance)

\begin{tabular}{|c|c|c|c|c|}
\hline Subject & Red & Blue & Green & Yellow \\
\hline 1 & 3.6990 & 0.0000 & 3.5441 & 2.4785 \\
\hline 5 & 3.3012 & 0.0000 & 3.6990 & 0.0000 \\
\hline 9 & 4.0414 & 3.6990 & 3.3012 & 3.6990 \\
\hline 13 & 3.0004 & 0.0000 & 3.3012 & 3.1765 \\
\hline 17 & 3.4772 & 2.6998 & 0.0000 & 0.0000 \\
\hline \multirow[t]{2}{*}{21} & 4.0004 & 3.0004 & 3.0004 & 3.9777 \\
\hline & Blue & Yellow & Red & Green \\
\hline 2 & 3.4772 & 3.3981 & 3.8451 & 3.3012 \\
\hline 6 & 0.0000 & 2.6998 & 3.0004 & 0.0000 \\
\hline 10 & 3.7782 & 3.7782 & 4.0792 & 3.3981 \\
\hline 14 & 0.0000 & 0.0000 & 0.0000 & 0.0000 \\
\hline 18 & 2.6998 & 2.6998 & 0.0000 & 3.3012 \\
\hline 22 & 3.3981 & 2.3996 & 3.0972 & 3.0004 \\
\hline
\end{tabular}




\begin{tabular}{l|l|l|l|l}
\hline Subject & Green & Red & Yellow & Blue \\
\hline 3 & 2.9036 & 3.1763 & 0.0000 & 3.3981 \\
7 & 3.5441 & 2.6998 & 0.0000 & 0.0000 \\
11 & 3.3981 & 3.6021 & 3.0004 & 2.6998 \\
15 & 4.0969 & 4.0212 & 2.8457 & 2.8457 \\
19 & 2.6998 & 3.5441 & 2.6998 & 3.3981 \\
23 & 4.1304 & 3.7782 & 3.3012 & 3.5533 \\
\hline & Yel10w & Green & Blue & Red \\
\hline 4 & 3.0004 & 4.0000 & 0.0600 & 0.0000 \\
12 & 0.0000 & 0.0000 & 0.0000 & 0.0000 \\
16 & 3.7782 & 2.3996 & 0.0000 & 0.0000 \\
20 & 3.9421 & 4.0212 & 3.3012 & 3.9778 \\
24 & 4.1904 & 4.1383 & 4.0414 & 4.3979 \\
\hline
\end{tabular}


Original Data: Heart Rate

(Change from resting rate, in terms of beats per minute)

\begin{tabular}{l|c|c|c|c}
\hline \hline Subject & Red & Blue & Green & Yellow \\
\hline 1 & 0 & 0 & -12 & -4 \\
5 & -2 & -6 & +4 & -12 \\
9 & 0 & 0 & 0 & 0 \\
13 & 0 & +2 & 0 & 0 \\
17 & -4 & -2 & -2 & 0 \\
21 & -6 & 0 & -2 & +2 \\
\hline 18 & Blue & Yellow & Red & Green \\
22 & +24 & -8 & -2 & -2 \\
10 & +2 & +2 & -2 & 0 \\
\hline 2 & +2 & +2 & +2 & +2 \\
\hline & 0 & -6 & -2 & 0 \\
\hline
\end{tabular}




\begin{tabular}{|c|c|c|c|c|}
\hline subject & Green & Red & Yellow & Blue \\
\hline 3 & -10 & 0 & 0 & 0 \\
\hline 7 & +2 & -6 & -4 & -6 \\
\hline 11 & +2 & +2 & +2 & 0 \\
\hline 15 & 0 & +4 & 0 & $\cdot 0$ \\
\hline 19 & 0 & -2 & +4 & 0 \\
\hline 23 & -2 & +2 & +2 & -2 \\
\hline & Yellow & Green & Blue & Red \\
\hline 4 & -2 & 0 & -2 & 0 \\
\hline 8 & -6 & -2 & +4 & -4 \\
\hline 12 & -4 & +10 & -8 & -2 \\
\hline 16 & 0 & +2 & -2 & 0 \\
\hline 20 & 0 & -2 & 0 & +4 \\
\hline 24 & +2 & -4 & -2 & 0 \\
\hline
\end{tabular}


Original Data: Respiration Rate

(Change from resting rate, in cycles per minute)

\begin{tabular}{l|c|c|c|c}
\hline \hline Subject & Red & Blue & Green & Yellow \\
\hline 1 & -2 & -4 & -6 & -2 \\
5 & -2 & 0 & 0 & 0 \\
9 & -4 & +2 & -2 & 0 \\
13 & 0 & 0 & +2 & 0 \\
17 & -2 & -2 & +2 & +2 \\
21 & +2 & 0 & -6 & +2 \\
\hline & Blue & Yellow & Red & Green \\
\hline 18 & +4 & 0 & 0 & 0 \\
22 & -10 & +4 & 0 & 0 \\
14 & 0 & -2 & 0 & -2 \\
\hline & +2 & +2 & 0 & -2 \\
\hline
\end{tabular}




\begin{tabular}{|c|c|c|c|c|}
\hline subject & Green & Red & Yellow & Slue \\
\hline 3 & -2 & -4 & -6 & 0 \\
\hline 7 & -2 & -2 & -2 & 0 \\
\hline 11 & 0 & 0 & $C$ & +6 \\
\hline 15 & -2 & 0 & 0 & 0 \\
\hline 19 & 0 & 0 & 0 & 0 \\
\hline \multirow[t]{2}{*}{23} & -2 & +2 & $+\frac{1}{2}$ & +2 \\
\hline & Yellow & Green & Blue & Red \\
\hline 4 & 0 & 0 & +2 & 0 \\
\hline 8 & -6 & 0 & 0 & 0 \\
\hline 12 & -6 & 0 & 0 & 0 \\
\hline 16 & -6 & -8 & -2 & -2 \\
\hline 20 & 0 & +2 & +2 & +6 \\
\hline 24 & -2 & 0 & 0 & +2 \\
\hline
\end{tabular}

